Soto ARANGO, D. y URiBE, J. T. (2002). «La Ilustración en el virreinato de la Nueva Granada», en Universidad e Ilustración en América. Nuevas perspectivas, Edición Coordinada por M. C. VERA. Universidad de Córdoba. Córdoba, Argentina, Universidad Nacional de Córdoba 2002, pp. 131-158.

Soto ARANGO, D. (2002). «La política del 'Despotismo Ilustrado' en la educación superior en el virreinato de la Nueva Granada», en Revista SYNTHESIS. Cadernos do Centro de Ciencias Sociais. Universidade do Estado do Rio de Janeiro, pp. 19 a 28.

Vargas Lesmes, J. (1989). Historia de Bogotá. Conquista y Colonia. Tomo II. Bogotá: Salvat Villegas Editores.

Zambrano Arias, A. y Miranda De Leon, P.(1989). Don Pedro Martínez de Pinillos en Mompox. Sincelejo: Compugraficas. 



\title{
EL SÍMBOLO DE UN ROBÍN HOOD VENGADOR EN EL OCCIDENTE DE COLOMBIA
}

\author{
Álvaro ACEBEDO TARAZONA \\ Universidad Tecnológica de Pereira
}

\begin{abstract}
RESUMEN: Como un fenómeno de las sociedades agrarias, Colombia fue uno de los países con mayores casos de bandolerismo en América Latina y el mundo, en especial el centro occidente de su actual territorio. Precisamente, en el municipio de Quinchía y poblaciones vecinas se creó la leyenda y casi el mito de un vengador social que asumió la causa de los campesinos minifundistas cafeteros y de los miembros del partido Liberal, perseguidos por una perversa alianza entre el Estado, la policía, el ejército y el partido Conservador. Este bandolero, además, se invistió de una especie de halo de "Robín Hood de los bosques" para encarnar una larga lucha de resistencia indígena desde los tiempos coloniales hasta la actualidad. Explicar el fenómeno del Capitán Venganza en este largo proceso de resistencia, verbigracia del contexto político y social en el cual surgió el bandolerismo social no sólo en Colombia sino en el mundo, es el propósito de este artículo.
\end{abstract}

PALABRAS CLAVE: Bandolerismo, campesino, Colombia, Quinchía, violencia, historia política.

ABSTRACT: Like a problem of the agrarian societies, Colombia was the one of countries with greater cases of banditry in Latin America and world, in special the center the West of its present territory. Indeed, in the municipality of Quinchía and neighboring populations invented the legend and almost the myth of a social avenger who adopted the cause of the farmers coffee small farm ownwers and the members of the Liberal party, persecuted by a perverse alliance between the State, policeman, army, and the Conservite Party. This brigand, besides, adopted of a species of I haul myself of Robín Hood of wodds to incarnate one long fight of indígena resitance from the colonial times to the present time. To explain the problem of Capitán Venganza in this long process of resistance, for example of the political and social context in which surgió social banditry not only in Colombia but the world, is the objective of this article.

KEY WORDS: banditry, peasant, Colombia, Quinchía, violence, politics history.

"Los hombres pueden vivir sin justicia, y en general se ven obligados a ello, pero no pueden vivir sin esperanza".

Hobsbawm, Bandidos ${ }^{1}$

Los caminos de la vida están siempre llenos de sorpresas, más aún los del investigador social animado por su asaz manía de preguntar, indagar. Cuando

${ }^{1}$ Hobsbawm, Eric (2001). Bandidos. Barcelona: Crítica, p. 69. 
llegué a la población de Quinchía, jamás imaginé encontrarme con una historia de resistencias y simbolismos tan arraigados, menos con la memoria viva de un "vengador social" a la usanza del Robín Hood de los bosques reales de Inglaterra que robaba y mataba para defender la causa de los necesitados y oprimidos.

Pero así como desde un comienzo pudo entusiasmarme la historia de este pueblo de estirpe indígena, mucho antes a otros los había animado a escribirla. "La historia de Quinchía me ha atraído como un imán -relataría a finales de los años ochenta Alfredo Tobón Cardona en su libro Quinchía mestizo-; su comunidad es algo especial en Colombia. Sobrevivió a los Españoles, a los Caucanos y a los Antioqueños y hasta a la violencia propiciada o tolerada por el Estado. Aunque perdió lengua, dioses y costumbres, conservó la unidad y su vocación comunitaria. Por su tierra pasaron Pizarros y Tascones, Gómez y Restrepos y al final quedaron, en primera línea, batallando por su comunidad, los Tapascos y los Vinascos, los Aricapas y los Guapachas, de las primeras estirpes nativas"2.

Es cierto. Los nombres y en especial los apellidos de una parte apreciable de los moradores de este poblado aún remiten al habla autóctona. Esto lo pude constatar casi de inmediato cuando leí la lista de estudiantes del programa de Etnoeducación y Desarrollo Comunitario que desarrollaba allí nuestra Escuela de Ciencias Sociales, avalado por la Universidad: Aricapas, Tapascos, Largos, Guapachas, Ladinos, Trejos, Pescadores, Tonuzcos saltaron en la lista, al igual que su presencia de rostros mestizos cuando atendían al llamado por sus nombres y apellidos ${ }^{3}$.

Pero leer los símbolos no es tarea fácil. Menos los remanentes del devenir de este pueblo que nos llega fragmentado, roto, hecho pedazos. Recomponer las imágenes o conceptos que se hacen presentes al exterior de una sociedad (representaciones), ya sea a través de los mitos, leyendas o la escritura (escasa por demás en nuestras sociedades), es como armar un rompecabezas, sólo que al final

${ }^{2}$ CARDona, Tobón, Alfredo (1989). Quinchía Mestizo. Pereira: Fondo Editorial del Departamento de Risaralda, p. 8.

3 Ibid., pp. 105-106. En 1919, el gobernador indígena del resguardo de Quinchía se llamaba Juan Bautista Quebrada, y los apellidos más comunes eran: Tapasco, Ladino, Aricapa, Trejos, Bañol, Chiquito, Velasco, Manso, Quebrada, Suárez, Guapacha, Bartolo. Otros apellidos eran: Gañán, Gaspar, Guarumo, Vinasco, Utima, Mápura y Arce. Aclara Alfredo Tobón Cardona que algunos de aquellos apellidos tienen raíces españolas y fueron tomados de prelados, funcionarios $\mathrm{o}$ encomenderos. Entre ellos, Trejos, deformación del castizo Trejo; Velazco fue un sacerdote que ejerció en Quinchía y Ríosucio; Ladino es un apellido español aplicado a judíos conversos; Vinasco es conocido en Santander, Colombia y España; el gentilicio Quebrada apareció a finales del siglo XIX en cierta zona del resguardo, posiblemente llegó de San Bartolo, en Pácora Caldas. 
se tiene la sensación de que las piezas no han encajado como debieran. Aún más difícil es tratar de discernir la manera cómo piensa un grupo social que ni siquiera hace inteligible al exterior sus percepciones de la realidad (mentalidad). Y si a todo esto se agrega la imprescindible lectura del entramado económico, ideologías, tensiones y luchas políticas que construyen las representaciones y la mentalidad de una comunidad, una región, una nación, es enorme la tarea que le espera al investigador social.

Desde su origen, el nombre de Quinchía, tal vez vocablo de etimología aborigen pero de designación castellana por la cantidad de quinchos o defensas de guadua que encontró la hueste conquistadora a su paso, ya era una historia de vencedores y vencidos ${ }^{4}$. Robledo (1539) cambió el nombre de Guacuma por el de Quinchía y desde ese momento los indios Tapascos, Guaqueramaes y otros mudaron los nombres de sus pueblos por este toponímico al igual que ocurrió con los nombres de muchos otros grupos aborígenes.

Desde entonces, la historia de este pueblo y de sus vecinos podría escribirse como una historia de la resistencia indígena hasta su sometimiento y casi total extinción. No se trata de hacer una historia de cuentas o ajustes morales, pero sí de comprender que el proceso de conquista fue dramático para los dos bandos, más aún para el vencido. Como bien lo señala Ernest Gellner, la cultura es un sistema de restricciones que pone límites a una serie infinita de posibilidades, y el mundo sólo cobra existencia para quienes conceptualizan nuevas opciones, posibilidades no realizadas a través del lenguaje que se recombina en una gran variedad de modos $^{5}$. Precisamente, este lenguaje, el de la tradición oral, es el que le da vida a la historia del Capitán Venganza, para encarnar una larga lucha de resistencias hasta la violencia de los años cincuenta y la actual, de la cual los pobladores de la actual Quinchía no son plenamente concientes de su origen, menos de su largo proceso de transformaciones.

\section{DE LA RESISTENCIA INDÍGENA A LAS VIOLENCIAS}

En 1542, en las provincias conquistadas por Jorge Robledo, se presentó el primer intento de rebelión por parte de los indígenas con el propósito de quemar Cartago $^{6}$, la ciudad destinada a convertirse, muy pronto, en la más importante de

${ }^{4}$ Ibid., pp. 15-16.

${ }^{5}$ GELLNER, Ernest (1997). Antropología y politica. Barcelona: Gedisa, pp. 69-70.

${ }^{6}$ En este enfrentamiento murieron 96 personas, entre ellas dos encomenderos; 12 españoles, 12 esclavos negros y 70 indios yanaconas; véase: CARDONA, Tobón, Op. cit., pág. 18. Al respecto explica 
todo el territorio por el oro de los indios Quimbayas. En 1546 murió Jorge Robledo, a manos de otro conquistador, Sebastián de Belalcázar. En 1557, los indios se alzaron otra vez por la misma razón que en el pasado: el maltrato de los encomenderos $^{7}$. Por esta época también hubo alzamientos o juntas en algunas provincias cercanas (Bugas, Gorrones, Carrapas) y otras muy alejadas (actuales territorios de Huila, Santander).

En 1601, señalan los documentos y estudios sobre la cruenta y larga guerra de los pijaos (1570-1618), grupos de zitaraes, chocoes y pijaos atacaron sin éxito Cartago, Anserma y Arma. Cartago fue defendida por los vecinos, y Anserma, caso curioso, fue defendida por los indios de las encomiendas de Tapuya, Guática, Quinchía y Supía, creyendo que el ataque iba dirigido contra ellos ${ }^{8}$. Al año siguiente, más de quinientos pijaos asaltaron e incendiaron Ibagué, una ciudad al otro lado de la cordillera Central. Por la cercanía de esta ciudad con Cartago, Buga, Anserma y Cali, sus pobladores se llenaron de pánico. Un temor que no era infundado, pues muchas fueron las incursiones de estos indios pijaos (llamados así todos lo grupos belicosos que se asentaron en las partes altas de la cordillera ${ }^{9}$ ) en aquellas provincias capturando esclavos negros e indios yanaconas (guías), incendiando las cosechas de los indios adoctrinados ${ }^{10}$, atacando los precarios caminos por los que transitaban los víveres y mercancías ${ }^{11}$, obligando al abandono de ciudades, minas y estancias, pérdida de encomiendas y ocasionando la muerte

Víctor Zuluaga que la rebelión fracasó en dos ocasiones por las delaciones que hicieron las propias esposas de los caciques; véase: Zuluaga, Víctor (2002). Historia de Cartago la antigua: Provincia de Popayán. Pereira: Buda, pp. 60-62.

${ }^{7}$ ZuluagA, Víctor, Op. cit., pp. 62-63. Explica también Alfredo Tobón Cardona que en esta rebelión se aliaron quimbayas y carrapas, y que también buscaron el apoyo de los ansermas e indios panches al otro lado del río Magdalena. Los indios se reunieron en Acurumbí (Chinchiná, Caldas) y destruyeron Jerez de la Frontera (primera fundación de Buga). En Anserma varios caciques fueron presos antes de la rebelión, algunos de los cuales murieron; CARDONA, Tobón, Op. cit., pp. 18.

${ }^{8}$ Valencia Llano, Alonso (1991). Resistencia indigena a la colonización española. Cali: Universidad del Valle, p. 125.

9 “En este sentido el término 'pijao' no designaba una comunidad específica, sino que era aplicado a cualquier tribu belicosa que habitara la frontera interna que se había creado en la Cordillera Central y que separaba la Gobernación de Popayán y el Nuevo Reino de Granada"; véase: VALENCIA Llano, Op. cit., p. 96.

${ }^{10}$ Zuluaga, Op. cit., p. 67.

${ }^{11}$ El 30 de septiembre de 1574, por ejemplo, en el Cabildo de Cali se discutió la necesidad de proteger el camino que comunicaba con Cartago ya que era constantemente atacado por los indios"; véase: VAlENCia Llano, Op. cit., p. 115. 
de españoles e indios. Sólo hasta el año de 1639, el gobernador de Popayán, don Juan de Borja, logró la extinción definitiva de estos indios ${ }^{12}$. Antes de esta fecha, sin embargo, fueron muchísimas las expediciones contra los indios pijaos ${ }^{13}$, en un área de mil kilómetros de longitud desde Otavalo hasta Santa Fe de Antioquia. Las ciudades más afectadas fueron aquellas de frontera, pero el impacto de estas juntas indígenas afectó durante algo más de cincuenta años el vasto territorio de la Gobernación de Popayán, creando un estado de emergencia económico y sociocultural, aún hoy poco estudiado ${ }^{14}$.

Pese a tal estado del territorio, la resistencia de las comunidades indígenas, sometidas a través de la encomienda y los repartimientos, no afectó a los centros económicos y administrativos más importantes; a lo sumo, impidió por un tiempo la incorporación de los centros mineros del Chocó. La resistencia de los pijaos (coalición de yalcones, paeces, pijaos, sutagaos, panches, bugas y putimaes), en cambio, afectó a centros urbanos importantes como Buga, Cartago, Timaná, La Plata o Ibagué, tanto a sus minas y estancias como a sus encomiendas ${ }^{15}$.

Posterior a la pacificación de estos grupos indígenas, con la consecuente estabilidad en las minas del Chocó, no se conocen procesos de resistencia indígena como los anteriormente mencionados. Esto, por un lado, debido a la ausencia de estudios, pero también al origen de nuevas formas de resistencia difíciles, aunque no imposibles, de rastrear en las fuentes documentales. La historia social está por escribirse en Colombia, lo manifestó en su momento Germán Colmenares ${ }^{16}$ y reiteradamente lo ha dicho Jaime Jaramillo Uribe ${ }^{17}$. El crisol de "razas" del Nuevo Mundo no fue ajeno a la segregación, la exclusión de las castas y la limpieza de sangre. Los prejuicios por parte de la minoría blanca dominante, a su vez, crearon

12 Zuluaga, Op. cit., p. 151.

13 VAlencia Llano, Op. cit., pp. 105-106. El autor registra 57 expediciones contra los indios Pijaos sólo ente los años de 1538 a 1610.

${ }^{14}$ Una aproximación a este estado de emergencia económico y social, se puede leer en el libro de: Barona, Guido (1995). La maldición de Midas: en una región del mundo colonial, Popayán 1730 1830. Cali: Universidad del Valle.

${ }^{15}$ Valencia Llano, Op. cit., p. 96.

${ }^{16}$ Colmenares, Germán (1998). Varia: Selección de textos, Colombia, Tercer Mundo Editores, p. 52.

17 JARAMILlo URIBE, Jaime (2002). "El mestizaje y la formación de la sociedad latinoamericana", en JARAMILlo URIBE, Jaime, De la sociología a la historia: Obras completas: Bogotá: Universidad de los Andes, pp. 79-85. 
barreras hacia los otros grupos sociales: "El indio era perezoso en el siglo XVI y se había embrutecido en el siglo XVIII. Los mestizos, fuente inagotable de conflictos, y los pardos, pendencieros y borrachos"18. El deseo civilizador de las elites, como lo denomina Cristina Umaña en su libro Civilización y violencia ${ }^{19}$, sería una fuente inagotable de violencia no sólo física sino simbólica durante el siglo XIX colombiano.

Largos procesos de resistencia están esperando ser estudiados. Palenques y levantamientos también se conocieron, en especial en el sur occidente colombiano $^{20}$. La lucha por la tierra también ha sido una fuente inagotable de conflictos. Desde que se creó la política de resguardos colonial, las comunidades indígenas se vieron sometidas a invasiones frecuentes por parte de blancos pobres y mestizos $^{21}$. Como era de esperarse, el resguardo de Quinchía no fue la excepción, aunque la presión sobre sus tierras no se dio tanto en la época colonial sino en la republicana, concretamente hacia el año de 1851 y décadas posteriores ${ }^{22}$.

Desde entonces colonos antioqueños e indios debieron convivir en estas ricas tierras. La población de Quinchía tampoco fue ajena a las contiendas civiles del siglo XIX o la etapa de la violencia en los años cuarenta del siglo XX. Incluso, en algunos de sus pobladores pervive la memoria de un suceso con aires de rebelión, poco después de la guerra de los Mil Días (1899-1902), liderado por don Melquisedec Gómez Murillo, para cambiar el día principal de mercado hacia los

${ }^{18}$ COLMENARES, Op. cit., pp. 69-70.

${ }^{19}$ RoJAs, Cristina (2001). Civilización y violencia: La búsqueda de la identidad en la Colombia del siglo XIX, Bogotá, Norma.

${ }^{20}$ Para un estudio de los Palenques del suroccidente colombiano, véase: ZULUAGA, Francisco y BERMúDEZ, Amparo (1997). La protesta social en el suroccidente colombiano. Cali: Universidad del Valle.

${ }^{21}$ Cabe recordar que los terrenos adjudicados a los indígenas se les denominó resguardos. Los propósitos para crear estas áreas eran, por un lado, mantenerlos en policía cristiana y tratar de preservar sus costumbres; por el otro, asegurar la tributación. Los resguardos creados en esta región del centro-occidente, en el año de 1627, fueron: Supía-Cañamomo, San Lorenzo y La Montaña, en los actuales municipios de Supía, Marmato y Ríosucio; Quinchía-Viejo; Guática; Tabuya, en el actual municipio de Anserma (1627); Tachiguí, en el actual municipio de Belén de Umbría; Embera-Chamí, comunidad que ocupaba hasta finales del siglo XIX la parte alta de la cuenca del río San Juan y un área que hoy corresponde al municipio de Bagadó en el departamento del Chocó y a los municipios de Mistrató y Pueblo Rico en el departamento de Risaralda; véase: ZuluaGa, Víctor (1992). Vida, pasión y muerte de los indigenas de Caldas y Risaralda. Pereira: UTP, pp. 1-20.

22 Tobón CARDOna, Op. cit., pp. 23 y ss. 
domingos. Hoy es posible que el viajero se aloje en la hermosa y tradicional posada de Don Melqui's, propiedad de su hijo Sósimo.

Por las luchas de resistencia de los indígenas y las propias de los colonos antioqueños que se radicaron allí, sus pobladores se sienten distintos a sus vecinos. Desde la violencia de los años cuarenta, Quinchía tiene fama de ser liberal, y, en algunos casos, sus pobladores vesánicos. En los años cincuenta y sesenta, fortín de bandoleros donde no quedaba un solo godo (conservador). Hoy la fama de Quinchía no es muy distinta, aunque sus circunstancias sí. Corredor de los grupos subversivos (FARC, ELN, EPL) y asiento de paramilitares, en cruenta guerra por el territorio, las listas de sentenciados, que se publican en las esquinas de la plaza o en cualquier casa, y los muertos, pareciera una historia de nunca acabar, es la otra historia de la Seguridad Democrática del presidente Álvaro Uribe. Las historias que se cuentan sobre estas masacres son para ponerle los pelos de punta a cualquiera. Como profesor del programa de Etnoeducación, pese a esa extraña ley del silencio que impera en los pueblos y campos colombianos azotados por la guerra (Uribe diría, por el terrorismo), escuché y asistí a más de una historia que de manera indirecta concernía al "normal" desarrollo de las clases: el estudiante que debió huir del pueblo porque salió en la Lista, aquél que no asistió porque subiendo de la vereda, debió presenciar cómo algunos hombres que venían con él fueron ajusticiados casi al instante y en el mismo lugar del que fueron bajados del carro, después de confrontar el número de sus cédulas con la Lista en un moderno computador portátil. La descripción sobre los ruegos, súplicas de los "ajusticiados" frente a sus verdugos, y la sordina de las balas se queda corta ante tanta impunidad. “¿Dónde estará Venganza?”. Pareciera que exclamaran los ojos de muchos pobladores de Quinchía ante la impotencia y la desesperanza. "Tenía un corazón tan grande que cuando lo velaron no cupo en el cajón", es posible escuchar en susurro cuando ya hay cierto aire de confianza con el visitante.

Sobre este vengador es muy conocida aquella historia narrada por el sacerdote Tamayo, hacia el año de 1958, cuando llegó a la población de Quinchía y los campesinos de la región lo recibieron manifestándole, más o menos, lo siguiente: "no señor cura, nosotros lo respetamos mucho, pero aquí no necesitamos por el momento autoridades... No nos hace falta el Alcalde, ni el cura, ni el ejército, porque para eso tenemos a Venganza. Venganza si nos respeta, nos defiende y nos quiere" 23 .

${ }^{23}$ Ibid., p. 146. 
Claro que no todo es color de rosa cuando se trata de evocar las hazañas del Capitán Venganza. Para las poblaciones vecinas de filiación al partido conservador, que se vieron combatidas por este bandolero social y otros como Pedro Brincos, Desquite, Sangrenegra, Tarzán (en el Tolima), Chispas o Efraín González (en el Quindío), Mosco y Zarpazo (Norte del Valle), Venganza fue uno más que representaba la muerte y el terror. Una especie de Cid Campeador que llevaba a todos los conservadores al "matadero", mientras las autoridades de Quinchía le hacían entradas triunfales a su héroe victorioso, Sir Medardo Trejos Ladino, con la anuencia de las comunidades religiosas, los cursillistas y las indias no embarazadas ${ }^{24}$. Para Luis María Bartolo, alias "El Brujo", sobreviviente "milagroso" de la ira de Venganza porque desobedeció con otros tres compañeros de cuadrilla una orden suya, aquel indio de pura cepa era un dictador y su voluntad era la ley en un Estado débil y cobarde que no supo imponer el orden en un vasto sector del occidente del Viejo Caldas, hoy poblaciones de Quinchía, parte de Ríosucio y Anserma y algunas veredas de Santuario, Guática y Balboa ${ }^{25}$. A nuestro bandolero social tampoco le va muy bien en la tradición oral recogida en aquellas poblaciones de filiación conservadora que se sintieron perseguidas hasta por su sombra. En estas versiones, Venganza polarizó el centro occidente del país, reactivó la guerra liberal-conservadora, asoló con ataques nocturnos a todos los municipios de su radio de acción y, al igual que en su momento lo hicieron los conservadores, se alió con las familias adineradas liberales para arrebatarles o comprarles a precios muy bajos la tierra a sus oponentes ${ }^{26}$.

El contexto de esta violencia ha sido escrito por varios investigadores sociales. Detrás de la venta forzosa, el despojo de tierras y bienes, el asesinato, la apropiación de cosechas y semovientes, el incendio de casas, la destrucción de sementeras, la coacción física, las migraciones masivas, también venía el comerciante que compraba el café robado o decomisado, el mismo que especulaba con la tierra o adulteraba las pesas ${ }^{27}$. Como era de esperarse, la violencia desató, al decir de Carlos Miguel Ortiz, las antiguas formas de dominio social y el papel de

${ }^{24}$ Documento del Archivo Personal de Ricardo de los Ríos, Pereira, julio de 2004.

25 CARdona Tobón, Alfredo (2004). Indios, curas y maiceros. Manizales: Hoyos Editores, pp. 74-76.

${ }^{26}$ Ríos, Ricardo de los (2004). Entrevista.

27 MeERTENs, Donny (2000). Ensayos sobre tierra, violencia y género. Bogotá: Universidad Nacional, pp. 138-139, 148-149. 
las estrategias individuales ${ }^{28}$. En el primer caso, numerosos jefes políticos se vieron, de un momento a otro, desplazados, mientras la población buscó nuevas alianzas y lealtades para sobrevivir. En el segundo caso, la violencia creó una sociedad de ricos emergentes sacando provecho de los negocios o simplemente de las circunstancias. Si por un lado la sociedad se disolvía, por el otro se recomponía. La economía cafetera se urbanizó, la violencia se ruralizó y los partido políticos se convirtieron en la única forma de identidad. No es por ello extraño que estos bandoleros sociales, pese a lo prepolítico de su identidad ideológica, tengan adscripciones partidarias, especialmente con el liberalismo. Las primeras formas de organización fueron las cuadrillas de autodefensa. "A una masacre o a una emboscada de tropas ejecutada por una cuadrilla liberal en la vereda, respondía otra masacre en cualquier lugar liberal de la zona de donde se sospechaba procedían los provocantes" $" 29$. Estas cuadrillas no se diferenciaron mucho de los denominados pájaros $^{30}$, que identificaban más a los grupos violentos organizados de conservadores. Con el tiempo la pajaramenta era tan grande que se utilizaba para designar indistintamente a los conservadores o liberales ${ }^{31}$.

De manera que en este cuadro de recomposición social, los bandoleros en un comienzo fueron vistos como salvadores. Sobre todo, porque la propia economía cafetera minifundista y hacendataria los sostuvo y no debieron recurrir a la violencia para hacer los recaudos. Se dice que en 1958, Venganza alcanzó a tener mil hombres bajo su mando, a través de un sistema de cuotas mensuales que cobraba a los campesinos tanto pobres como adinerados para el sostenimiento de sus cuadrillas ${ }^{32}$.

Para los campesinos de Quinchía de aquella época, y para la mayoría de los actuales, incluyendo a la población urbana, Venganza no es otra cosa que un Robín

28 Ortiz SARMiento, Carlos Miguel (1985). Estado y subversión en Colombia: La violencia en el Quindio años 50. Bogotá, Uniandes-Cerec.

${ }^{29}$ Ibid., pp. 185-186.

${ }^{30}$ Ibid., p. 189. "En el Quindío la utilización de pájaros suele considerarse como la transferencia de una práctica proveniente del Valle del Cauca. Las versiones sobre el sentido del apocamiento difieren en matices; el decir más común es que el apelativo deriva de la condición original de aves de paso, mercenarios volantes, que iban de un centro a otro para realizar trabajitos; esta última palabra, con la cual se significa en el argot los asesinatos consumados por encargo tiene una connotación pecuniaria: todo trabajo es pagado, y aquél generalmente lo era también".

31 Ibid., p. 193.

${ }^{32}$ MeERTENS, Op. cit., p. 173-174. 
Hood de los bosques del centro occidente colombiano. Hoy es imposible saber qué pensaba en realidad este defensor de los campesinos minifundistas cafeteros de esta región, menos aun de qué causa se sentía defensor. Tal vez de la causa liberal, pues dicho bandolero estuvo muy influenciado por Pedro Brincos (Roberto González Prieto $^{33}$ ), quien era la misma encarnación, como sucedió con otros bandoleros de esta época, de las guerrillas liberales que no se desmovilizaron en la amnistía de Gustavo Rojas Pinilla o en la "paz" que saldó el pacto entre liberales y conservadores, para crear el Frente Nacional.

De los bandoleros sociales del centro occidente del país, Venganza fue el más parecido a un Robín Hood que luchaba por la causa de los justos. Su vida sigue siendo un misterio; de ahí su halo de leyenda. En su vida no se le llevaron mayores procesos judiciales, poco se conoce de su trabajo legal y menos de su vida en el monte. Todas sus acciones remiten a la construcción de un símbolo.

\section{VENGANZA: UN BANDOLERO SOCIAL DEL CENTRO- OCCIDENTE DE COLOMBIA}

¿Defendía Venganza la causa de los indígenas? No es claro dar una respuesta afirmativa o contraria al respecto. Es muy curioso que para los habitantes actuales de Quinchía, hay que insistir en ello muchos de rostros y apellidos indígenas, no hay casi nada que los una con su pasado de ancestro aborigen. Esto lo pude constatar en los debates de clase cuando les pregunté a los estudiantes del programa: ¿qué pensaban de los pocos indios sobrevivientes en Quinchía?, y casi todos al unísono respondieron que, en primer lugar, aquellos ya no eran indios, y, en segundo lugar, que algunos de ellos eran unos aprovechados de su falsa condición étnica, engreídos y hasta mala clase (malas personas). Es claro que para la mayoría de los habitantes actuales de Quinchía hay muy poco que los vincula con su pasado indio. Muchos de ellos, incluso, se consideran de raigambre antioqueña más que de cualquier otra cosa.

Esto se puede explicar por la lucha, ya señalada, entre los indios del resguardo y los colonos antioqueños que presionaban por sus tierras y las minas de oro, sal y carbón. Hacia los años veinte del siglo pasado, la población de la parcialidad

33 En 1957, Pedro Brincos se desplazó desde Líbano hacia Caldas para organizar las guerrillas liberales. Cuando Pedro Brincos abandonó la región, Venganza asumió el liderazgo en la región; véase: MeERTEnS, Op. cit. 172. 
aprovechaba muy poco el resguardo ${ }^{34}$. Nuevos colonos antioqueños demandaron aún más por el usufructo de estas tierras, y los indios del cabildo no tuvieron ningún reparo en venderlas paulatinamente. Luego llegaron los catíos de lengua Chamí a ocupar estas tierras hasta que los indígenas asentados de tiempo atrás y los recién llegados eran vistos como un solo grupo de brutos, ignorantes y sometidos. Las pocas tierras que habían quedado en manos de los indígenas se fueron subdividiendo hasta que en 1940 ya eran miles de minifundios. Ocho años después, el mestizaje era el común denominador y las autoridades decidieron acabar con el resguardo. Esta historia, contada por Alfredo Tobón Cardona, en el libro ya citado Quinchía mestizo ${ }^{35}$, remite a una etapa posterior no menos conflictiva: la recuperación de parte de la tierra por iniciativa ya no propiamente de los indígenas sino de los campesinos mestizos que se sentían explotados por ricos propietarios de Ríosucio y de Manizales ${ }^{36}$. Para los peones, en los alrededores de Mápura e Irra reposaban "las gotas de sudor y las hambres de los antepasados". Así mismo, estos peones no olvidaban que estas tierras, antes suyas, habían sido vendidas baratísimas por un cabildo indígena corrupto y en otros casos ocupadas contra la voluntad de los poseedores de las parcialidades ${ }^{37}$.

Por todo esto, no es extraño que el resguardo de Quinchía fuese el más afectado por la denominada primera etapa de la violencia liberal-conservadora en los años cincuenta. Quinchía, de mayoría liberal, estaba rodeada por municipios con poblaciones de mayoría conservadora ${ }^{38}$. Al principio, varias familias liberales tuvieron que huir del casco urbano y de las veredas por el terror que sembraron algunos miembros del partido conservador aliados con la policía. Pero, como bien lo señala Víctor Zuluaga, la reacción liberal no se hizo esperar y muy pronto Medardo Trejos, alias Capitán Venganza, se convertiría en el jefe indiscutible de la guerrilla en toda la región ${ }^{39}$.

${ }^{34}$ En 1919, un censo indígena arrojó un total de 2537 personas en el resguardo. En 1923, de los 6687 habitantes de Quinchía, 2000 eran indígenas tributarios; véase: CARDONA TOBÓN, Quinchía mestizo, Op. cit., pp. 105 y 107.

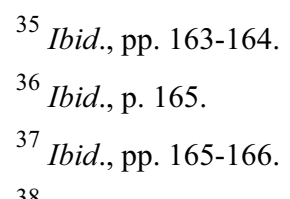

38 Zuluaga, Víctor (1992). Vida, pasión y muerte de los indígenas de Caldas y Risaralda. Pereira, Op. cit., p. 43. (texto de investigación presentado a la Universidad Tecnológica de Pereira; en la actualidad se encuentra editado: Buda, $2^{\mathrm{a}}$ edición, 1995). En el texto, Zuluaga dice que la violencia conservadora fue desatada en el pueblo por Antonio Sánchez, conocido dirigente conservador.

${ }^{39}$ Ibid. 
Hacia finales del decenio de los sesenta, luego de varias demandas por parte de algunos campesinos sin tierra y de viajes a Bogotá para reclamar sus antiguos derechos, años también en los que el Capitán Venganza se investirá de su halo de Robín Hood, el Instituto Colombiano para la Reforma Agraria (INCORA) por fin le entregó varias fincas en Quinchía ${ }^{40}$. Hacia 1985 la población rural del municipio ascendía a 21596 habitantes, ubicada en 77 veredas. Sólo tres veredas estaban ocupadas por personas de ancestro antioqueño, mientras que en las demás predominaba el ancestro nativo cuyo número ascendía a 21000 habitantes $^{41}$.

Hoy Quinchía sigue envuelto en un de halo conflicto y violencia. No por sus pobladores, pues si se trata de un grupo social que haya mantenido ciertas tradiciones comunitarias y de solidaridad, es ésta. El problema es que por ser un corredor entre el norte y el sur, el occidente y el oriente del país, en Quinchía convergen la violencia guerrillera, paramilitar, del Estado y la delictuosa. En los últimos días (agosto de 2004), un juez profirió resolución de acusación contra 54 de los 118 presuntos colaboradores del EPL. La prensa señala que la medida afecta al detenido alcalde de Quinchía, el ex alcalde y dos concejales, entre otros ${ }^{42}$. ¿Hasta qué término se puede ser ajeno a estos grupos subversivos, cuando el contacto con ellos es el diario vivir de la población?

El Capitán Venganza es tal vez el único puente entre los anhelos de paz y justicia social de los quinchieños de ahora y la resistencia aborigen del pasado. No se trata de un héroe de folletín ni de un personaje de cómic, Venganza es un símbolo de la memoria oral al igual que muchos de los bandoleros estudiados por Eric Hombsbawm ${ }^{43}$. Para este gran experto en el tema, el gran bandido siempre será "más fuerte, más famoso que el campesino corriente, y su nombre vivirá más tiempo que el de este", aunque no por ello será menos mortal ${ }^{44}$. Bandoleros como el Capitán Venganza siempre pertenecerán a la historia recordada. El símbolo que sobrevive a esa aspiración de alcanzar justicia, de pensar en un hombre nuevo, una "camaradería de hombres libres e iguales, la invulnerabilidad ante la autoridad y la protección de los débiles, de los oprimidos y de los engañados" ${ }^{45}$.

\footnotetext{
${ }^{40}$ Cardona ToBón, Quinchía mestizo, Op. cit., p. 168.

${ }^{41}$ Ibid., p. 169.

${ }^{42}$ EL TIEMPO, agosto primero de 2004, p. 2-2.

${ }^{43}$ Hobsbawm, Op. cit., p. 150.

${ }^{44}$ Ibid., p. 152.

45 Ibid., p. 154.
} 
Dejemos entonces que sean las actuaciones de este máximo líder de la resistencia campesina, en el centro occidente de Colombia, las que hablen por sí mismas a través de una breve semblanza que nos deja la reconstrucción oral de su leyenda ${ }^{46}$.

\section{EL CAPITÁN VENGANZA: SEMBLANZA DE UNA TRADICIÓN ORAL}

En el año de 1939, en el seno de una familia de ancestro indígena, y en una vereda llamada la Ciénaga del municipio de Quinchía, Risaralda-Colombia, nació Medardo Trejos Ladino. Su infancia transcurrió tranquilamente como la de cualquier joven de la región. Pasaba sus tardes de infancia entre juegos y trabajos propios de la agricultura que le enseñaba su padre.

Hacia el año de 1945, Medardo Trejos, tal vez apenas lograba deletrear sus primeros dictados, gracias a estudios que realizaba en la escuela El Murrupal, la más cercana a su casa. Era un niño de carácter tranquilo y tímido, del cual nadie tenía nada que decir; ni siquiera sus profesores de escuela expresaban queja alguna. $\mathrm{Su}$ padre, Jesús María Trejos, un campesino que se dedicaba a la cacería y a la agricultura, y que en algún momento de su vida tuvo que participar en la guerra de los Mil Días, no tuvo más qué enseñar a su hijo que el cuidado de la tierra, pues de su militancia en la guerra no le quedó nada.

Luego de cumplir con sus labores en el campo, el joven Medardo se reunía algunas tardes con su amigo de infancia Faustino Largo a realizar las tareas para la escuela y a compartir recorridos aventureros por el campo. Era un muchacho alegre, le gustaba rezar, bailar. Era muy alegre, andaba con papá. Con el viejo, como lo llamaba él, jugábamos columpio, burro y de todo, cuenta Emélida Trejos, hermana de Medardo.

Un día cualquiera, doña Laura Rosa Ladino, madre del Joven Medardo, se enteró por sorpresa de que su hijo de 8 años había partido de la casa en busca de

\footnotetext{
${ }^{46}$ La semblanza del Capitán Venganza se ha reconstruido de la tradición oral, luego de entrevistar a varias personas que lo conocieron o vivieron en la misma época de sus actuaciones. Para la reconstrucción de su semblanza también ha sido gran utilidad los apartes referidos a este bandolero social en el libro de CARDONA ToBÓn, Quinchía mestizo, Op. cit., págs. 147-158 y las tesis de grado de Baena Arce, John Jairo y Manso Trejos, Luz Marina (2004). Quinchía: Historia y su Cultura, Tesis de grado presentada al programa de Etnoeducación y Desarrollo Comunitario de la Universidad Tecnológica de Pereira, y ACHIPIZ, Gilberto y otros (1985). La violencia política en Quinchía: caso Capitán Venganza, Tesis de grado presentada a la Escuela de Ciencias Sociales de la Universidad Tecnológica de Pereira.
} 
bienestar y nuevos sueños. El jovencito nunca advirtió que se marcharía, simplemente preparó sus cosas personales y se fue. Según su madre, había terminado estudios primarios cuando decidió partir a rumbos que ni siquiera él conocía. No obstante, hay quienes afirman que sólo estudió hasta segundo o tercero de primaria.

Algunas personas del pueblo comentan que por esta época anduvo por el departamento del Tolima. Su madre, por el contrario, dice que el joven estuvo rondando regiones aledañas a Quinchía. De aquella época no se conocen mayores datos de Medardo Trejos.

Diez años después, en 1955, todavía siendo un adolescente, Medardo regresó al municipio de Quinchía. Se encontró nuevamente con su familia y con la alegría de sus hermanos menores que no lo conocían. Era un joven de gran fortaleza física y moral. Se caracterizaba por asistir puntualmente a las ceremonias religiosas que se celebraban en el pueblo y por disfrutar de los festejos y los bailes. Sin dar explicaciones ni recuentos relacionados con su ausencia, el joven regresó nuevamente a los trabajos de la tierra, en compañía de su padre, y a la cotidianidad campesina de la época.

Se reencontró con sus amigos de infancia, y con ellos asistió tanto a festejos como a reuniones de corte político que realizaban los grupos armados organizados. Muy pronto, Medardo Trejos se hizo reconocer en el Municipio de Quinchía como un joven valiente y defensor de la comunidad. La preocupación por el bienestar de su gente, las precarias condiciones económicas de su familia y su espíritu libre e inquieto llevaron a Medardo a enfilarse en grupos armados liberales hasta que se llegó la hora de tomar decisiones, y la de Medardo fue la de ingresar a las guerrillas. A él no lo impulsaba nada al principio. La gente llegaba y lo convidaba a reuniones y como era un muchacho fuerte terminó metido, defendiendo, eso sí, el Partido Liberal.

En sus contactos con el partido liberal, es conocido por el comandante general Pedro Briceño en el año de 1957, un jefe guerrillero que se encontraba liderando, por esos días, diferentes grupos liberales organizados que ya existían en la región. Para entonces, Medardo tenía unos 18 años de edad y en cuestión de poco tiempo se hizo con el liderazgo.

Si bien son diversas las versiones que se han adjudicado al origen de su alias, aún es memorable su sobresaliente desempeño en un combate que se presentó en la quebrada de Marcela y del cual salió ileso para convertirse en el temido y respetado CAPITAN VENGANZA. 
Ya para ese momento, el Capitán Venganza se veía como el héroe salvador y protector de los campesinos. Sin embargo, para el gobierno y los senadores conservadores, esta sociedad al margen de la ley era considerada como una república bandolera. Se inició entonces la etapa de persecución contra Venganza, pues en la medida que crecía su leyenda de Robín Hood vengador entre los campesinos y simpatizantes de la región, para el gobierno y los conservadores de las poblaciones vecinas éste era un simple delincuente que tenía amedrentado a todo el mundo porque en las veredas y en Quinchía sólo se hacía lo que él dijera. Ni siquiera la autoridad del Alcalde era tenida en cuenta para tomar decisiones. Según datos confirmados por el historiador Zuluaga, así se expresaba un campesino conservador de Venganza: En Naranjal mandan los bandoleros. Alli no baja ni el policía ni el Alcalde, ni nadie que a los criminales no les guste. Ellos se tomaron esa región y todas las familias son encubridoras. Les reparten comida, les arreglan la ropa y les dan dormida.

Sin lugar a dudas, Venganza era el líder campesino liberal más famoso de la región. Su vida transcurría entre escondites, batallas y amores. Pasaba poco tiempo en su casa, tan sólo iba en las noches a visitar a su familia, a cambiarse de ropa y a comer lo que su madre le ofrecía. Salía a altas horas de la noche para evitar encuentros con el ejército, que se mantenía en vigilancia de la casa. Ellos no lo conocían, por eso él muchas veces se paseaba con tranquilidad por la plaza del pueblo vestido como un campesino corriente, con botas de caucho, machete en la cintura y sombrero aguadeño. Ésta era otra forma de camuflaje, pues su apariencia era sencilla y bastante indígena como la de cualquier lugareño: de complexión fuerte, no muy alto, moreno, de facciones indígenas y cabello lacio. Otras veces, disfrazado de anciano o de mujer, recorría las calles de Quinchía y Ríosucio. En las veredas Naranjal, Botero, Moreto, Juan Tapado, Opiramá e Irra también sentían su presencia, pero muy pocos conocían su rostro.

Cuenta su familia que cuando Medardo llegaba a la casa se veía como un hombre tranquilo y silencioso que disfrutaba de la lectura de revistas, de escuchar radio y de las conversaciones que sostenía con su padre. Leía revistas que yo no sabía de qué se trataban y mantenía andando con un radio, asi como andan hoy en día los trabajadores. Y eso que en esa época casi no existían esos radios, cuenta su madre. Una tarde casi es capturado por el ejército. Se encontraba tranquilo en la casa cuando lo sorprendieron y tuvo que salir corriendo por la puerta del patio, hasta esconderse en unos matorrales.

Por estos hechos, su leyenda se acrecentaba. Sin poder mágico alguno, aparecía y desaparecía libremente como un Robín Hood de los bosques; y cabalgaba entre los árboles y las montañas camuflándose en la neblina, para no ser atrapado por el 
sol ni su enemigo. Sus aventuras y hazañas hicieron que Venganza fuera temido y respetado por los habitantes de toda la localidad. Quienes le temían y lo odiaban, por el contrario decían: Ese es un asesino y un sanguinario.

Cuenta su madre Laura Rosa Ladino que el día que casi lo atrapa el ejército en su casa, les ocasionó mucho susto, porque los comandantes del ejército entraron y requisaron todos los rincones buscando al Capitán Venganza. Sin embargo, gracias a las habilidades de su hijo, éste se había salvado. Él era muy rápido, ese día se voló por el patio y ellos no lo volvieron a ver, pero mentira; él estaba ahí (sonríe).

Este tipo de acontecimientos empezaron a ser muy frecuentes en la casa de doña Laura Rosa. En el periodo de tiempo comprendido entre los años 1959 hasta 1961, la familia vivió en constantes tensiones de vida o muerte. No sólo por las preocupaciones que ocasionaban las persecuciones al joven Venganza, sino también por las de su hermano José Noa Trejos, alias Matallana, quien era un año menor que Medardo y quien también había incursionado en grupos armados campesinos. Día y noche el coronel Valencia los perseguía. Una vez vinieron a la casa a buscarlos; me preguntaron por ellos y me dijeron que era que yo los negaba. Yo les dije: Mire de aquí de la puerta pa' afuera no respondo por lo que hagan mis hijos en la calle; uno responde por ellos aquí adentro en la casa. Otro día entró el coronel Valencia hasta la cocina y me dijo: Esta casa está buena para volarla así como estamos aquí nosotros; entonces yo le dije: bien pueda vuélela, pues yo me muero y usted también... todos nos vamos.

Pasaba el tiempo mientras las acusaciones contra Venganza alcanzaban vuelo nacional, pero la familia Trejos continuaba una vida normal. Las hermanas de los jóvenes seguían en labores cotidianas; y el padre y la madre se dedicaban a esperar a sus hijos y a trabajar en el campo. Aunque fueron muchas las amenazas nunca pensaron en abandonar su territorio. Por el contrario, su madre manifestaba: $A$ mi no me daba miedo, pa' que voy a decir que me daba miedo. Si me hubiera dado miedo me hubiera ido de aquí. Ellos se cansaron de amenazarnos y nosotros no nos íbamos... Nos tendrían que sacar muertos. No obstante, las preocupaciones de la madre por la muerte de sus hijos eran latentes. El papá les vivía diciendo: muchachos no se confíen tanto que, vean, el ejército está encima de ustedes. Y ellos decían: que va... Cuenta doña Laura Rosa, mientras mira tímidamente una cámara de video que la intimida.

La fortaleza física de Medardo Trejos, la fama y el poderío que había adquirido, en casi dos años de militancia, lo habían convertido en un hombre tan desaforado que llegó a desafiar la muerte incluso en presencia de su madre. Tranquila má que la hora algún día se nos va a llegar. 
Para este momento, Venganza ya era tan conocido por tanta gente que hasta había logrado generar relaciones de amistad con el alcalde y dos sacerdotes, que según su madre se llamaban José María Torti y Celestino Aventino. Con ellos, quienes se preocupaban por el destino del joven, viajó a España para iniciar terapias de resocialización. Todo fue inútil, porque pudo más la cultura y el amor por su tierra. El decía que se había aburrido por allá y que por eso se vino. Regresó a Quinchía y continuó el recorrido por veredas y poblados aledaños en medio de combates.

Para el año 1961, el Capitán Venganza se movía como pez en el agua por su territorio. Casualmente, el día 5 de junio aquel año, se encontraba en la vereda Miracampos, cerca al cerro de Batero. Vereda que se caracterizaba por ser una comunidad en su mayoría conservadora. Era un domingo, día en que se celebraba el descanso en la comunidad. El joven Medardo se encontraba en la cantina del señor Buenaventura García tomando cerveza con sus compañeros de lucha y celebrando como buen paisano el descanso. Todo transcurría normalmente; hasta el hecho de que la patrulla del ejército se encontrara rondando la vereda era habitual para sus habitantes.

Eran casi la una de la mañana y en el ambiente hacía rato que se venía escuchando la canción que más le gustaba a Medardo, pues la hacía repetir y repetir como vaticinando su muerte. Sonaron siete balazos... a las cinco de la mañana. El ejército se bajó de la patrulla para hacer su control acostumbrado y entró en la cantina; a uno de los soldados le pareció reconocer al Capitán Venganza; sin embargo, no estaba seguro, pero de igual forma lo llamaron y lo condujeron por la vía al Higo, unos cincuenta metros del puesto de Batero. Allí, buscando certeza, hicieron arrodillar al joven para preguntarle que si era el Capitán Venganza. Él les contestaba tranquilamente: No, yo no soy. El agente insistió en pedirle identificación. Sin más preguntas ni interrogantes dispararon a sangre fría para no correr el riesgo de equivocarse. No fueron siete, sino dos los balazos que dieron muerte al héroe y máximo líder de la resistencia campesina del municipio de Quinchía, Risaralda-Colombia ${ }^{47}$.

${ }^{47}$ Los relatos sobre la muerte del Capitán Venganza coinciden en las versiones de los distintos investigadores. Esto lo que dice Donny Meertens: "Del Capitán Venganza no se conoce más historia, ni de su trabajo legal, ni de su vida en el monte. Así como se ignora el origen social del popular bandolero, así también quedan ocultos los propósitos finales de su doble actividad. Sólo se sabe que el 5 de junio de 1961, a las seis de la tarde, sin ninguna compañía, Venganza tomó su última copa en una cantina veredal de Quinchía, a la cual había llegado a caballo. Allí lo sorprendió una patrulla del ejército que le exigió rendición, sin que él opusiera resistencia alguna. Poco después, en el camino, el jefe bandolero fue dado de baja, es decir, conforme las prácticas de la época, le fue aplicada la 
Corrió rápidamente la noticia por toda la región. La sorpresa de su muerte alarmó al pueblo, pues ésta era la oportunidad de conocer el rostro real del fantasma de la Venganza. Eran ya las siete de la mañana cuando un hermano de doña Laura Rosa llegó a tocar su puerta para avisarle que habían matado a su hijo Medardo. La madre se encontraba tan preparada para la noticia que mientras se organizaba para correr a las exequias de su hijo dijo: Ya lo mataron, ya que vamos a hacer. Si corremos no lo volvemos y si no corremos, siempre lo alcanzamos.

Su cuerpo fue trasladado a la casa de don José Ladino. Allí lo velaron. Durante todo el día no se veían más que desfiles de lugareños, quienes curiosos se acercaban al féretro. Muchos por afecto lloraron su muerte, otros por odio se alegraron de que por fin el villano hubiese apagado sus armas y sus ojos para siempre. Hoy reposan, en el cementerio principal de Quinchía, las tumbas de los hermanos Trejos Ladino, pues transcurrido un mes de la muerte de Venganza fue asesinado por las tropas del ejército nacional su hermano menor, alias Matallana.

Aquel hombre humo, que se desvanecía cuando se le intentaba tocar y que se escurría por los montes quincheños, dejó una historia abierta en la tradición oral de Quinchía.

\section{EL BANDOLERISMO SOCIAL: UN ESTUDIO DE CASO EN PERSPECTIVA COMPARADA}

Para investigadores como Donny Meertens, el bandolerismo en Colombia en el periodo entre 1958 a 1964 no tuvo paralelos en la historia occidental del siglo XX. Al comienzo de los años sesenta había más de 100 bandas activas, con el apoyo militante o pasivo de las comunidades rurales de su misma identidad partidaria ${ }^{48}$. Si

siniestra ley de fuga"; véase: MEERTENS, Op. cit., p. 180. Esta es la versión de Tobón Cardona: "E1 2 de junio de 1961 el capitán Jesús Ríos Aristizábal, comandante de la compañía destacada en Quinchía, en operación de emboscada, dio de baja a Gerardo Largo Correa, alias Gavilán Negro, el último sobreviviente de cuadrilla organizada. El 5 de junio le tocó el turno a Medardo Trejos Ladino, alias el Capitán Venganza... La patrulla condujo a Venganza hacia el puesto Batero, 50 metros abajo le dieron muerte. Uno de los proyectiles entró por el homoplato izquierdo y salió por la región pectoral. Otro balazo entró por la tibia saliendo cerca del tobillo. Medardo falleció instantáneamente. La fuerza pública quiso hacer creer que Venganza había atacado a la patrulla y herido a un suboficial y a un soldado"; vease: CARDONA TOBÓN, Op. cit., pp. 157-158.

${ }^{48}$ MeERTENS, Op. cit., pp. 143-144. Unos años atrás, Eric Hobsbawm, con base en estudios de investigadores colombianos, hace el siguiente balance: "En Colombia en el momento culminante de la anárquica guerra civil de los años posteriores a 1948 había no menos de cuarenta bandas de campesinos armados, lo que representa, calculando de 10 a 20 miembros para cada banda de ladrones -número que es sorprendentemente uniforme a través de las épocas y de los continentes-, unos $400 \mathrm{u}$ 
bien explicar el proceso político para la conformación de tal estado de bandolerismo único en el mundo implicaría hacer otro texto, es importante por ahora decir que estos bandoleros fueron jefes militantes de origen campesino, provenientes de una primera fase (1948-1958) de la violencia de las guerrillas liberales que enfrentaron a los conservadores. Se está hablando entonces de un bandolerismo político, para diferenciar esta categoría de aquella prepolítica y modesta en sus alcances, que hace Eric Hobsbawm cuando dice que "el bandolerismo en sí no constituye un programa para la sociedad campesina, sino una forma de autoayuda para escapar de ella en determinadas circunstancias. Los bandoleros, dejando aparte su voluntad o capacidad de rehusar la sumisión individual, no tienen más ideología que la del campesinado (o parte del campesinado) de que forman parte. Son activistas y no ideólogos o profetas de los que quepa esperar nuevos enfoques o planes de organización social o política"49.

Además de la procedencia política (guerrilleros liberales campesinos) de los bandoleros de esta región, en el periodo mencionado (1948-1964), sus procesos de lucha y organización se caracterizaron por la incorporación masiva de adolescentes que habían crecido en el ambiente de la violencia y por el rápido paso de unas alianzas partidistas nacionales (partido liberal) a unas más localizadas en las que el trato se establecía estrictamente con los jefes "naturales" de las regiones o gamonales $^{50}$.

Valga también decir que esta expresión del bandolerismo en el centro occidente de Colombia se inscribe en un fenómeno universal, el cual se da en sociedades basadas en la agricultura y en condiciones de explotación por parte de grandes señores hacia los campesinos ${ }^{51}$. El escalofriante fenómeno de la violencia en Colombia, sin embargo, creó elementos de violencia patológica únicos en el mundo, que al final condujeron a la anarquía del bandolerismo hasta hacerlo epidémico. Un país sediento de sangre, llamaría Eric Hobsbawm a este periodo de la historia de Colombia en el que se presenciaron prácticas terribles como las de descuartizar a los prisioneros en trozos pequeños (picar a tamal) ${ }^{52}$. Prácticas todas

800 hombres para un área de unos 23.000 kilómetros cuadrados, 166 asentamientos rurales y quizás 600.000 o 70.000 campesinos"; véase: HoBSBAwM, OP. CIT., p. 36.

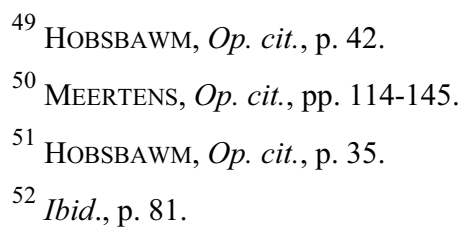


estas que son inseparables de la venganza ${ }^{53}$, como en el caso de nuestro vengador que asumió este mote para vengar a todos los liberales.

Los bandoleros de 1958-1964 en el centro occidente de Colombia son la segunda generación de hijos de aquella violencia que sobrevivió a la ceniza de sus casas, los cadáveres de sus padres y los cuerpos violados de sus madres y hermanas $^{54}$. De otra parte, la mayoría de ellos no se incorporó a los movimientos guerrilleros que nacieron en los años sesenta (FARC, ELN, EPL).

México, Brasil y Colombia son los países del bandolerismo en América Latina. Pero si bien México fue la quintaesencia del bandolerismo en el continente, Brasil la fiel expresión del bandolerismo epidémico, Colombia fue la triste expresión del bandolerismo sangriento ${ }^{55}$.

Venganza es el prototipo del bandolero social del que nos habla Hobsbawm. De igual forma, el contexto social, político y económico en el que surgió resiste casi todas las comparaciones con el bandolerismo social en el mundo ${ }^{56}$. Como todos los bandoleros, el Capitán Venganza es un hombre soltero, joven y sin cargas familiares. Su extracción es más rural que urbana. La causa que lo anima a rebelarse es consecuencia de un largo proceso de resistencia indígena y luego campesina frente a la desigualdad e injusticia. Es cierto que este bandolero surge en un contexto político, pero sus concepciones son más prepolíticas que otra cosa. De ahí que no se conozcan de él concepciones organizativas de gran alcance o ideas revolucionarias, pues él encarna las reivindicaciones de una comunidad específica en un marco tradicional. También es cierto que se ve atraído por el universo del poder, pero él representa la forma más primitiva de la protesta social, pues sus concepciones del mundo están aferradas a la localidad de la que es indisoluble. De ahí que la forma de su muerte sea absurda para objetivos revolucionarios o de organización política, pero muy consecuente con lo que había representado en su corta vida. Como todos los bandoleros fue justiciero, destructor o salvaje $\mathrm{e}^{57}$. Le sirvió a la sociedad y a los grupos de poder local hasta que se convirtió en una

\footnotetext{
${ }^{53}$ Ibid., p. 87.

${ }^{54}$ Ibid., p. 85.

${ }^{55}$ Ibid., pp. 173-175.

${ }^{56}$ Hobsbawm, Eric (2001). Rebeldes primitivos. Madrid, Crítica, p. 33.

57 Se dice que "la violencia arreció en 1960, cuando Quinchía encabezó la lista con 33 muertes violentas y Santuario registró 22 asesinatos, cometidos según la prensa de Manizales por las cuadrillas destacadas por Venganza"; véase: CARDONA ToBón, Quinchía mestizo, Op. cit., p. 157.
} 